\title{
La tierra para el que la trabaja: política y género en la reforma agraria chilena*
}

\section{Heidi Tinsman**}

\begin{abstract}
RESUMEN
La reforma agraria chilena, un proyecto de modernización y transformación social radical, incluía tanto las mujeres como a hombres campesinos a través de un modelo de "familia moderna" en cual el hombre se transformaría en buen proveedor para la familia y productor para la nación, mientras la mujer se transformaría en una dueña de casa moderna. Este proyecto beneficiaba a las mujeres casadas pero las hizo económicamente más dependientes de los hombres, lo que generó agudos conflictos conyugales. Para las mujeres solteras y jóvenes, la reforma agraria fue distinta, les ofrecía más oportunidades sociales y de trabajo. Esto creó una nueva cultura juvenil rural que produjo nuevos conflictos entre madres e hijas.
\end{abstract}

Palabras clave: Reforma agraria / mujeres campesinas / relaciones de género / sexualidad de campesinas jóvenes / modelo familiar.

\section{The land for the one who works on it: policies and gender in the chilean agrarian reform}

\begin{abstract}
The Chilean Agrarian Reform, a project of modernization and radical social transformation, included peasant women as well as male farmers through a model of "modern family" in which the man would become the breadwinner for the family and the producer for the nation, while the woman would become a modern housewife. This project would benefit married women, but it made them more economically dependent on their husbands, which caused serious marital conflicts. For the single and young women, the Agrarian Reform was different, it offered more social and work opportunities to them. This created a new rural youth culture that caused new conflicts between mothers and daughters.
\end{abstract}

Key words: Agrarian Reform / peasant women / gender relationships / sexuality of young peasant women / family model

* Ponencia presentada en el seminario "Reforma y contra reforma agraria el campo chileno; resultados y consecuencias a 41 años de la Reforma Agraria en Chile". Organizado por el Departamento de Trabajo Social de la Universidad Católica Silva Henríquez, realizado el día 24 de junio de 2008 .

** Estado Unidense. Ph.D. Yale University. Profesora de Historia, University of California Irvine. Directora, Universidad de Califorina en Chile. Correo electrónico: hetinsma@uci.edu 


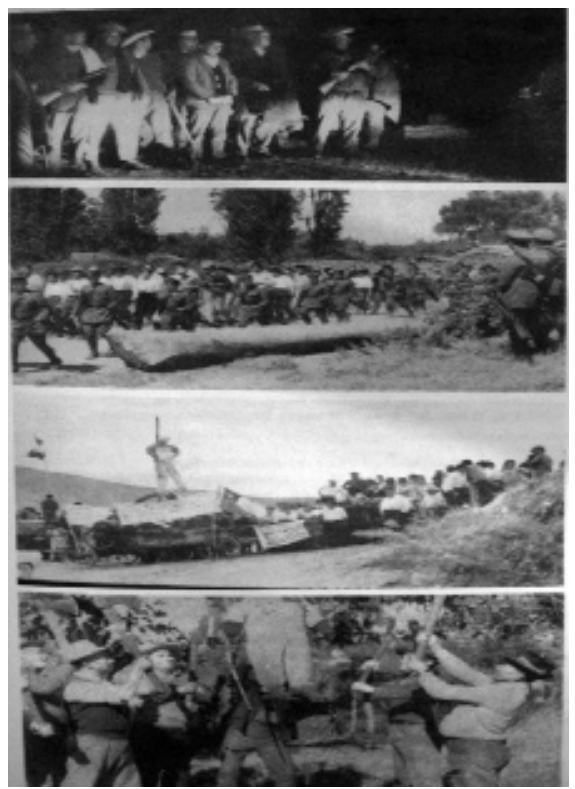

\section{Antecedentes}

Se ha dicho mucho sobre los problemas de la reforma agraria, sus errores y fracasos. Pero también se deben reconocer sus éxitos ya que la reforma agraria chilena se caracteriza por ser como un proyecto profundamente masivo y mayormente democrático. En menos de nueve años, se expropió la mitad de la tierra agrícola, se sindicalizaron más de un cuarto millón de campesinos, se triplicaron los sueldos rurales, se construyeron diez miles de casas, además escuelas y hospitales. Sobre todo, por primera vez le dio voz en la política nacional, a la gente más pobre y postergada de la nación. (Bengoa, 1990; Huerta, 1989; Loveman, 1976)

En la década del '60, la reforma agraria se realizó en muchas partes del mundo. Pero la reforma agraria chilena fue, proporcional y políticamente, la más extensiva y menos violenta, dirigida por gobiernos democráticamente electos. Ello en contraposición a los países donde vemos reformas profundas en que todas corresponden a revoluciones armadas: Cuba, China, Rusia, México, Vietnam, por ejemplo.

En una mirada retrospectiva, lo sorprendente de Chile no es que haya habido un golpe militar en 1973, sino que existiera una cultura política en los años '60, en se creía posible reorganizar profundamente la estructura de la propiedad privada, bajo de condiciones de democracia. 
En un intento de dimensionar el fenómeno, se podría decir que la reforma agraria chilena sería equivalente en los Estados Unidos que el gobierno en Washington expropiara todo California, Texas, Arizona, y todo el Medioeste. Ciertamente, la única reorganización de la propiedad privada que se ha hecho en dicho país, de escala similar a la reforma agraria chilena, fue la abolición de la esclavitud, que corresponde a la propiedad privada de seres humanos, que era la base de nuestro latifundio. Pero se lo hizo solamente después de una guerra civil que costó medio millón de vidas.

La reforma agraria chilena ha sido importante para re-construir la democracia chilena en los últimos 20 años. Aunque ahora no se habla de "reorganizar la propiedad privada," pero sí de sueldos éticos, de pensiones dignas, acceso a la educación, el derecho de trabajadores a compartir las ganancias de exportaciones, etcétera. La reforma agraria, haya o no tenido éxito, representa casi el único precedente democrático rural sobre el cual trabajadores del campo siguen imaginado el futuro.

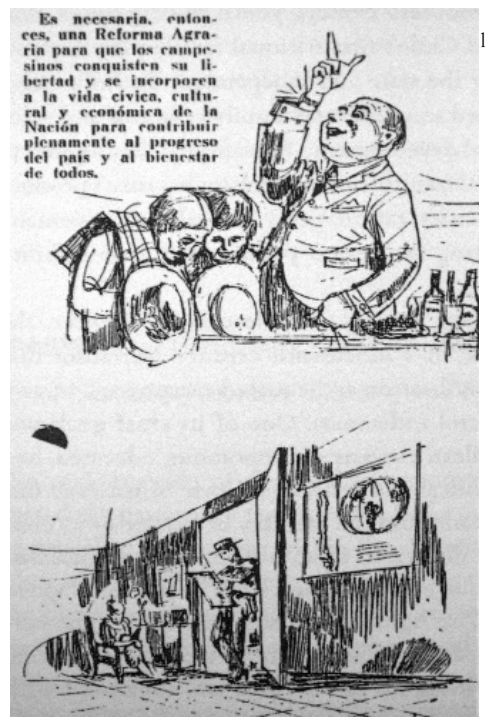

1 Esta imagen corresponde a la "Acción Sindical Chilena," una organización formada por Padre Alberto Hurtado en 1950, con un claro pensamiento católico social, pero compartido por todos los colores políticos. Hay un "antes" y "después" de la reforma agraria. Antes, los inquilinos son sometidos al patrón. Gorro en mano, mirando al suelo. Después, el hombre está visto de traje de huaso, el sombrero bien puesto, leyendo el diario. Su mujer, sentada, también está leyendo, un libro. Quiere decir que los dos tienen acceso a la educación. La casa tiene un mapa de Chile y del mundo. Los horizontes del campesinado claramente son mucho más amplios con la reforma agraria. Campesinos, hombres y mujeres, son ciudadanos, participando en construir tanto una patria como un mundo mejor. 


\section{Relaciones de género en la reforma agraria}

Un tema un poco más complejo corresponde a las relaciones entre hombres y mujeres en la reforma agraria, ya que esta impactó profundamente a las campesinas. Las mujeres fueron movilizadas a escala nacional en una forma sin precedentes: cientos de miles participaban en Centros de Madres, Clubes Juveniles, Juntas de Vecinos, programas de alfabetización, etcétera. Muchas de ellas formaron ollas comunes durante huelgas y tomas de tierra, jugando roles clave en tomas de viviendas. También, las mujeres fueron usuarias del primer programa nacional de Planificación Familiar, impulsado bajo el Gobierno de Eduardo Frei, que extendió los métodos anticonceptivos al campo. Las campesinas no fueron excluidas de la reforma agraria, sino que ellas se beneficiaron del mejoramiento de salarios, salud, educación, y vivienda que trajo la reforma. (Tinsman, 2002; Valdés, 1992; Garrett, 1982.)

Sin embargo, las mujeres fueron incluidas de un modo muy distinto respecto de los hombres, y eso las hizo más vulnerables económicamente más dependientes de los hombres. Existiendo distinciones entre las mujeres casadas y las jóvenes y solteras:

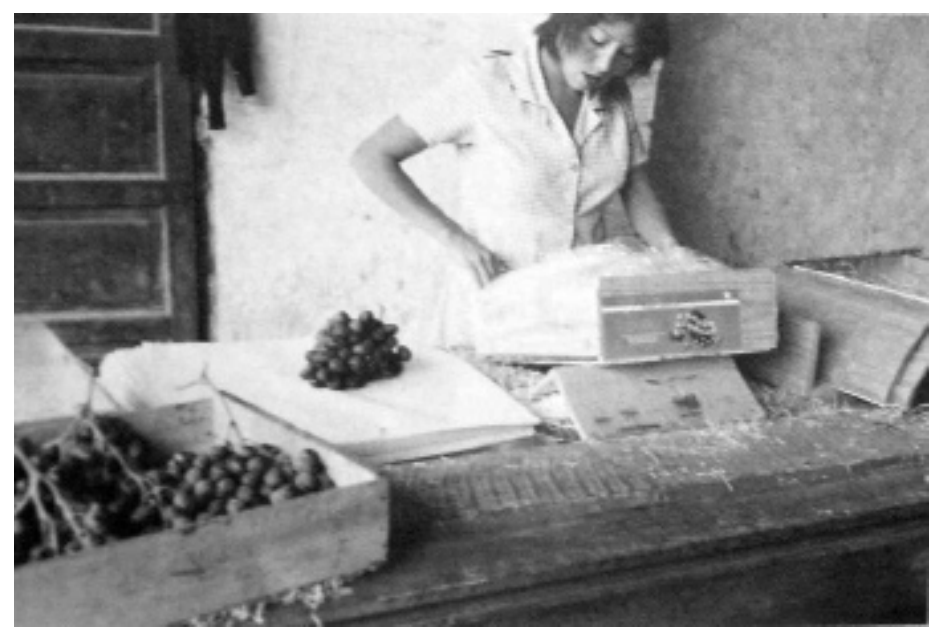

La reforma agraria incluía a las mujeres, pero claramente privilegió a los hombres como actores principales. La ley de reforma agraria estipuló que los receptores de tierra serán "jefes de hogar," lo que casi siempre se entendía como hombres. Para calificar, se tenía que mostrar experiencia como trabajador permanente u inquilino, sien- 
do la gran mayoría hombres. El 95\% de los títulos de tenencia de la tierra fueron recibidos por hombres. Asimismo, más del $90 \%$ de los miembros de asentamientos era hombres. Aún en los Centros de Reforma Agraria, una entidad creada por la Unidad Popular específicamente para incluir mujeres y afuerinos, un $90 \%$ eran hombres. Igualmente, un $90 \%$ de los socios de sindicatos eran hombres. Ello se refleja también en que casi todo el nuevo trabajo permanente va dirigido a los hombres. (Valdés, 1992; Garrett, 1982)

No es casualidad, que el lema de la reforma agraria era "la tierra para él que la trabaja." También se hablaba de "convertir el humilde campesino en su propio patrón, "de hacerse "un verdadero hombre." La reforma agraria fue, en parte, un proyecto para construir una nueva masculinidad campesina. Una masculinidad más independiente, menos humillada, más moderna, hasta militante. (Tinsman, 2002.)

Pero la reforma agraria también intentaba construir un nuevo tipo de mujer. Se planteaba la modernización del campo no sólo para reorganizar la tierra, sino también para modernizar la cultura campesina. Como parte de esto, se promovía un modelo de "familia moderna" en que los hombres campesinos se transformarían en verdaderos proveedores para las familias y productores del bien nacional. Las mujeres campesinas se transformarían en una dueña de casa moderna: mucho más educada, capaz de criar niños y administrar los bienes familiares según normas higiénicas y racionales.

Por otra parte, se concebía a las mujeres como un actor cívico, participando en juntas de vecinos, centros de madres y apoyando actividades sindicales. Este modelo no imaginaba a las mujeres sometidas a los hombres, sino al contrario: hombres y mujeres eran vistos como socios del progreso.

De acuerdo a esto, los cursos de capacitación dirigidos por organizaciones estatales como el Instituto de Desarrollo Agropecuario (INDAP), la Corporación de Reforma Agraria (CORA), o Promoción Popular (programa de movilización popular bajo el gobierno de Frei) se proponían que hombres y mujeres debían comunicarse mejor, colaborar en la toma de decisiones, y mostrarse respeto mutuo. El machismo violento era visto como "atrasado," parte de la mentalidad latifundista. La prensa sindical y la iglesia proponían que los hombres debían entregar sus salarios a sus esposas y mantenerlas informadas sobre sus actividades sindicales. 
Mientras tanto, el programa de Planificación Familiar ofrecía talleres que promovían la idea de que los hombres debían consultar las mujeres sobre la frecuencia de relaciones sexuales; que las mujeres debían tener voz sobre la cantidad de niños que querían tener; y acceso a métodos anticonceptivos. Sobre todo, se proponía que la "paternidad" era una responsabilidad compartida, y que los hombres le debían a su mujer más fidelidad sexual, aun cuando si no fuera fidelidad completa. (Tinsman, 2002; Jiles, 1992.)

Esta visión de "familia moderna" y "roles complementarios" fue compartida tanto por la izquierda y marxistas, como por católicos y democratacristianos. Lo que se constituye en un hecho muy interesante de la reforma agraria bajo el gobierno de Allende, comparada con otros proyectos socialistas (como Rusia o China). En Chile el socialismo no pensaba mayormente en liberar las mujeres campesinas a través de su rol como trabajadora, sino a través de su rol como madre. Se generaron discusiones muy importantes durante la Unidad Popular, sobre la necesidad de crear más trabajo para las mujeres, pero eso estuvo más relacionado con la ciudad y el trabajo industrial, que con el campo.

En práctica, la izquierda comparte con la iglesia el proyecto de transformar a las campesinas en dueñas de casa modernas. Esta dueña de casa también iba a ser políticamente activa, militante en construir el socialismo. Pero el discurso es sumamente maternalista, muy influido por el proyecto católico y la doctrina social de la iglesia.

Esto es interesante porque no significa que las mujeres campesinas no trabajaran fuera de la casa en esta época, ya que ellas cultivaban la regalía o huerto que alimentaba la familia; trabajaban dentro del fundo durante las cosechas; y trabajan mucho en servicios domésticos. Incluso, hacia fines de los años ‘30, había un gran número de mujeres inquilinas. (Valdés, 1988; Aranda, 1981.)

Lo importante es subrayar que los roles de género promovidos por la reforma agraria no fueron un resultado automático ni natural de la organización del trabajo que ya existía. Eran también resultado de un proyecto ideológico y político: de cómo se imaginaba construir la modernidad en este tiempo.

Pero en la práctica esto fue más complejo porque muchos hombres se oponían darles poder a las mujeres, sobre en cómo ellos gastaba 
su salario (especialmente gastos en trago). Otros se oponían a que sus mujeres asistieran a reuniones políticas, que las ponían en contacto social con otros hombres.

Por otro lado, muchas campesinas estaban entusiasmadas con el modelo de familia moderna: Les gustaba el concepto de hombres como proveedores y que los hombres compartieran autoridad y obligaciones con ellas.

Como sabemos, la reforma agraria produce agudo conflicto social: de clase y político, pero también de género. En la provincia de Aconcagua, por ejemplo, los archivos judiciales muestran que casi se triplicaron durante la reforma agraria las denuncias de violencia doméstica por parte de las campesinas contra sus parejas. ${ }^{2}$

En historias orales, tantos hombres como mujeres mencionan un grave crecimiento en conflictos matrimoniales: peleas, violencia doméstica y abandono. ${ }^{3}$ Esto es un tema complejo en que destacan las razones especificadas en los juicios por estos conflictos, relacionadas con los conceptos de género promovidos por la reforma agraria. Por ejemplo, hay hombres que golpean a las mujeres porque ellas insisten en que él le entregue su sueldo, o porque reclaman ser informadas sobre las actividades de su marido. Otros conflictos provienen del hecho que algunas mujeres comienzan a asistir a clases de alfabetización sin consentimiento del marido, o porque ellas acuden a los consultorios de salud en busca de métodos anticonceptivos.

Esto no significa que este tipo de conflictos no existiera antes, sino que la reforma agraria produce nuevas expectativas en los roles familiares que mujeres y hombres comienzan a re-negociar. Paradójicamente, es precisamente en el aumento de los conflictos, donde vemos que algo está en juego. Por un lado, la reforma agraria había propuesto un modelo de familia moderna que le pareció adecuado a muchas mujeres campesinas. Pero por otra parte, la reforma agra-

2 El numero promedio de casos de "lesiones" denuciados por mujeres campesinas contra sus parejas en el Juzgado del Crimen de San Felipe fue de 12 en 1964, 34 en 1971, y 50 en 1973. (Registro de Crímenes, Juzgado de Crimen, San Felipe.)

3 Durante 1991 y 1998, realicé 70 historias orales con campesinas y campesinos. También examiné las historias orales hechas por autores como: Valdés, Aranda, Garrett, Montecino. 
ria potenció que las mujeres casadas fuesen económicamente más dependientes de sus maridos. El aumento en violencia doméstica refleja, en parte, el empeño de las mujeres en que los hombres cumplan con su nuevo rol, y la resistencia de éstos al cambio.

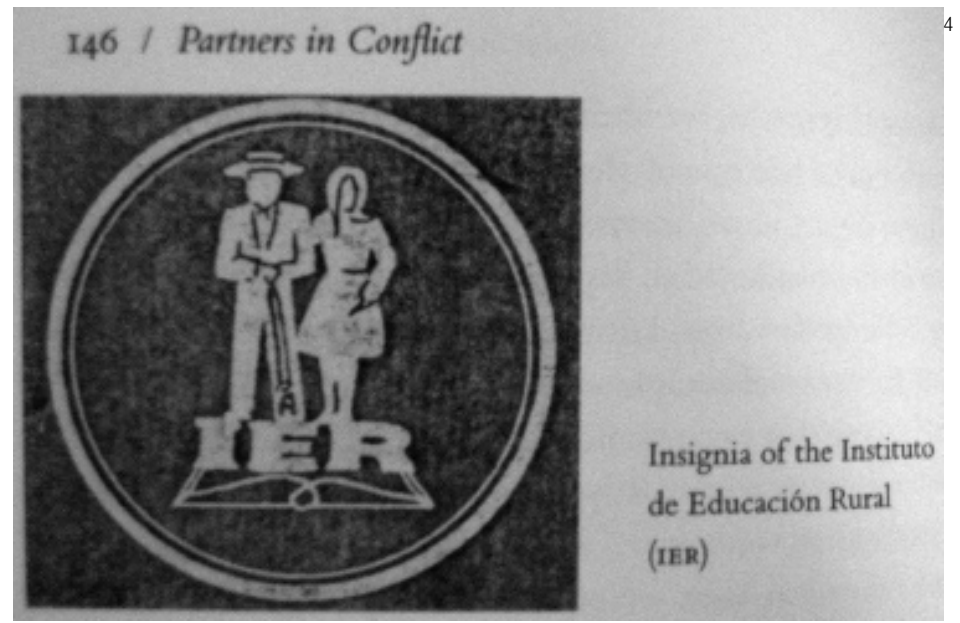

\section{Situación de campesinas jóvenes y solteras}

La situación de las mujeres jóvenes y solteras era diferente, ya que para ellas la reforma agraria abrió oportunidades económicas y sociales. Tanto el gobierno de Frei como el de Allende, promovía la idea de que "la juventud" tenía intereses netamente independientes de los adultos y que debían tener organizaciones propias. (Tinsman, 2001.)

Las adolescentes campesinas fueron a la escuela cinco o seis años más que sus madres. Las nuevas "escuelas agrícolas" fundadas por INDAP y CORA enseñaron a niñas tanto como niños sobre semillas híbridas e incluso a conducir tractores. Los partidos políticos tenían "ramas juveniles" con socios mixtos (hombres y mujeres). Los clubes juveniles tenían bailes donde la música tradicional de la cueca y la ranchera, lo que fue cambiado por la música de los Beatles y los Jaivas. Estos acentos urbanos se volvían más fuertes en verano

4 Esta imagen es el logo del Instituto de Educación Rural (IER), de pensamiento católico, pero compartido por todos colores políticos. Aquí la pareja es central. El progreso del campo está representado por la sociedad doméstica. Hombre y mujer parada sobre un libro, la educación. Pero cabe destacar que el hombre tiene en la mano una herramienta para producir, un azadón, mientras que la mujer tiene un su mano el brazo del hombre. 
cuando universitarios iban al campo a construir canales y a alfabetizar. De manera que la reforma agraria genera una cultura juvenil distinta y pone a las jóvenes rurales en un mayor contacto con el mundo urbano.

Además, la reforma agraria genera más trabajo para mujeres jóvenes: En el Valle de Aconcagua, por ejemplo, el número de mujeres trabajando en faenas temporales (cosecha y siembra) aumenta en un 400\%: Había 500 temporeras en el año 1964, y más que 2000 al final de la reforma agraria. (Censos Agropecuario, Aconcagua, 19641965 y 1975-1976). Asimismo, hay un aumento de mujeres trabajando en packings de fruta y conserva.

El dinero que ellas recibían por su trabajo muchas veces no era entregado completamente a familia, sin embargo, el trabajo no las hizo "independientes," pero si las daba oportunidades de hacer compras propias y de contar con recursos económicos para desarrollar actividades sociales en las localidades o ciudades más cercanas a su domicilio.

El aumento de las posibilidades laborales para mujeres jóvenes se debe en gran parte a la expansión de plantaciones frutales y de viñedos bajo el Plan Nacional de Desarrollo Frutícola. Esto fue mayormente en el sector privado, sin embargo, se implementó con subsidios estatales y como parte del proyecto más amplio de la reforma agraria. Es importante destacar que la exitosa fruticultura chilena de hoy, le debe algo muy importante a la reforma agraria. No fue producto solamente del régimen militar ni del neoliberalismo. (Gómez y Echenique, 1988.)

Algunas jóvenes que trabajaban como temporeras, comienzan a formar parte de sindicatos y participan en tomas de fábricas y packings. Debido a ello, es que al fin de la dictadura en los ' 80 , cuando re-nace el movimiento sindical, algunas mujeres que eran jóvenes durante el período de la reforma agraria, cuentan ahora con experiencia sindical y por ello juegan un rol importante en esos años. Generándose el protagonismo que tienen hoy las mujeres temporeras en las organizaciones del agro. (Tinsman, 2000; Valdés, 1988.)

Las oportunidades de trabajo y vida social para mujeres jóvenes durante la reforma agraria, generaron nuevos conflictos generacionales, especialmente entre madres e hijas. Las jóvenes comienzan 
a desafiar más abiertamente la autoridad materna. Se producen conflictos por quien va controlar el salario de la joven, peleas por las relaciones de pareja, las fiestas y eventos en los clubes juveniles. Aumenta significativamente el número de casos de jóvenes que abandonan el hogar paterno. Similar al incremento de casos de violencia doméstica, en los archivos judiciales, el número de casos de abandono de hogar se triplicó entre los años ' 60 al ' $73 .{ }^{5}$

No obstante, más que el aumento, lo relevante es el cambio de las razones para abandonar el hogar. En los años '50, los casos de abandono de hogar eran de niñas que huían de casa para casarse sin el consentimiento de sus padres, o para escapar situaciones de violencia intrafamiliar. Es decir que ellas cambiaban la casa paterna por la de un marido.

En contraste, durante la reforma agraria existían muchos más casos de chicas que huían temporalmente del hogar paterno, por razones de gozo más informal. Por ejemplo, hay muchachas que van a Valparaíso para pasar el fin de semana con sus parejas, pero vuelven. No tienen intenciones de casarse. Hay chicas que asisten fiestas en un asentamiento vecino, admitiendo que disfrutan la compañía masculina, pero que no tienen intención de establecer una relación de pareja estable, algunas declaran que hasta han fumado marihuana.

Vemos, también que aumentan casi al doble las imputaciones por casos de abusos sexuales. En su mayoría corresponden a denunciadas formuladas por la madre campesina quien declara que su hija fue violada. Sin embargo, en más que la mitad de los casos, la hija da testimonio que la relación sexual fue consensuada. Pareciera ser entonces, que las madres van a los tribunales a buscar la autoridad que sentían perdida sobre sus hijas.

Durante la reforma agraria, en 1973, el número de madres solteras adolescentes aumenta al doble respecto de lo que fue en $1955 .{ }^{6}$ De manera que podríamos decir, que para muchas madres preocupadas por la conducta desafiante de sus hijas, el problema no era simplemente moral.

5 Entre 1964 y 1970, había un promedio de 15 casos de "abandono de hogar" de hijas campesinas en el departamento de San Felipe. Entre 1970 y 1973, el promedio fue 35 casos. (Registro de Crímenes, Juzgado de Crimen, San Felipe.)

6 Registro de Nacimientos. Registro Civil San Felipe, Chile. 
La reforma agraria reforzó un modelo de familia en cual, para tener acceso a los beneficios de tierra y trabajo estable, una mujer tenía que tener una relación permanente con un hombre beneficiario. Las mujeres jóvenes tenían acceso a trabajo, pero temporal e insuficiente como para sostener a una familia.

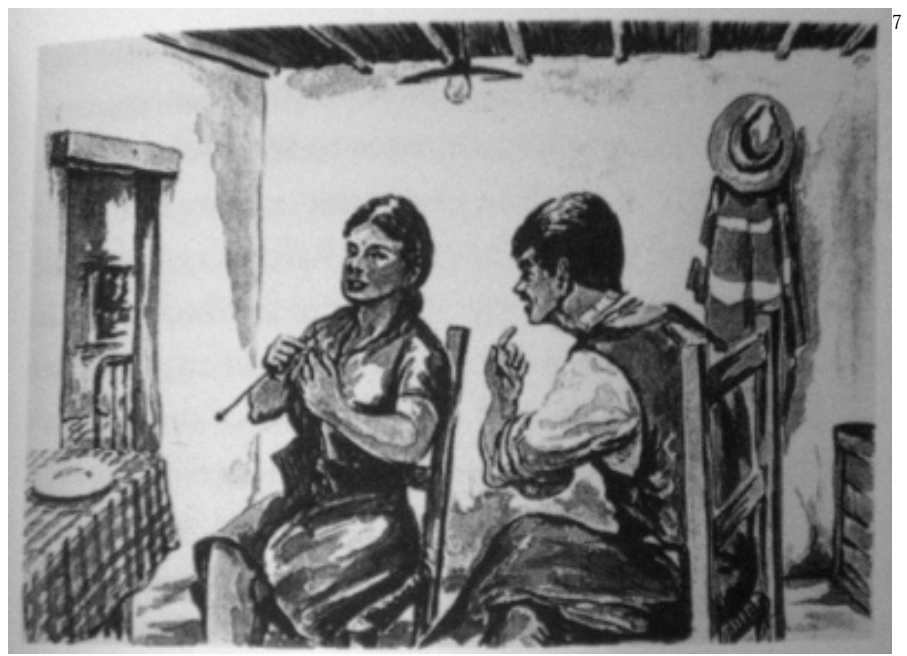

\section{Reflexiones finales}

Finalmente, se podría sostener que los ideales sobre "familia moderna" y "cultura juvenil" co-existieron en tensión con un tercer proyecto de género de la Reforma Agraria: Correspondiente a fomentar un movimiento militante de trabajadores hombres, intentando promover el liderazgo masculino como proceso político. A los hombres se les exigía no sólo a ser "buenos proveedores y esposos"; sino también ser hombres "políticamente combativos y militantes que mostraran lealtad a otros hombres en la lucha de clases". Como futuros dueños de la tierra, fueron llamados a mostrar su carácter al enfrentarse "de hombre a hombre" con el patrón; arriesgarse en huelgas y tomas de tierras. Esa fue la triple jornada de ser hombre: Buen marido; leal compañero de trabajo; militante en la lucha por la tierra. (Tinsman, 2002.)

$7 \quad$ Esta imagen es de un folleto de la CORA durante el gobierno de Frei: Representa claramente la buena comunicación matrimonial. El hombre vuelve del trabajo o de la huelga a contar a su mujer todo lo que pasó, le explica las razones de la reforma agraria. Ella está convencida, escucha atentamente mientras hace un trabajo productivo para la familia (tejer) 


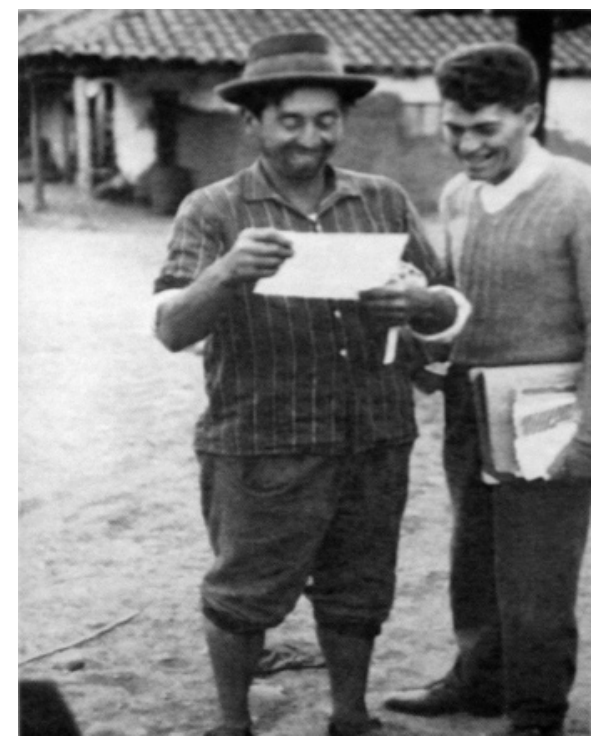

Durante la época de la Unidad Popular, los ideales de género de la reforma agraria fueron sometidos a una extraordinaria presión. Los hombres pasaban mucho más tiempo en reuniones, huelgas, y tomas. Al final, el rol masculino del compañero militante se hizo más urgente para muchos hombres que lo significaba ser "jefe de hogar, responsable." Muchas mujeres se sentían cada vez más "solas" y con sus familias "abandonadas." Al problema que les generaban las conductas desafiantes de las hijas, se sumaba el temor a que su pareja les fuera infiel y de los riesgos que implicaba su participación política.

En las historias orales, se evidencia la enorme diferencia entre la memoria de la reforma agraria de los hombres respecto de las mujeres. Ellos a menudo recuerdan la reforma agraria como una época tremendamente excitante, en la cual viajaron a otras partes del país por primera vez, conocieron a nuevas personas, y se sintieron considerados por los partidos políticos, el Estado y hasta por los patrones. A la vez, tienen recuerdos triunfantes de huelgas ganadas y del orgullo de ver sus niños y niñas con zapatos por primera vez. Estos recuerdos coexisten con otros muy amargos, de conflictos entre trabajadores y entre partidos políticos.

Por el contrario, las mujeres a menudo recuerdan la reforma agraria como tiempos de violentas peleas familiares, largos periodos de soledad; desconocimiento sobre lo que estaba pasando; traiciones sexuales de los hombres; y preocupación por las hijas. 
Esto no significa que no existan recuerdos positivos en las mujeres, ya que las experiencias de las jóvenes y solteras fue distinta a la de mujeres casadas. Tampoco en todos los hogares se vivió violencia intrafamiliar, sino que la memoria de conflicto que tienen muchas mujeres es un discurso, casi colectivo, no necesariamente un hecho que vivió cada una.

Habría un desacuerdo de género en la memoria de la reforma agraria, reflejada en las formas en que dicho proceso reforzó la dependencia de las mujeres hacia los hombres, aún cuando le ofrecía un atractivo modelo de familia moderna. Asimismo, la participación de los hombres en sindicatos y asentamientos los capacitó para responder al conflicto social a través de canales institucionales y políticos. Pero por el contrario, las mujeres estaban organizadas alrededor de identidades de "dueñas de casa" que las hacían más dispuestas a responder al conflicto social en términos de roles dentro de la familia: roles en que las obligaciones de los hombres hacia ellas, eran más decisivas que nunca.

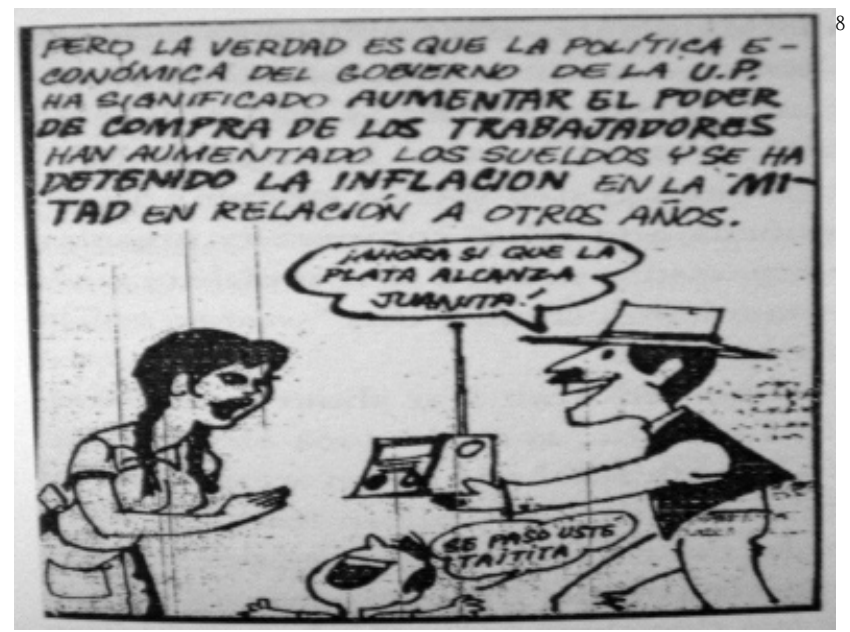

Ello no querría decir que las mujeres campesinas se hubiesen opuesto a la reforma agraria. Sólo considerando Aconcagua -una fortaleza de organización demócrata cristiana- vemos que más que un tercio de mujeres rurales votaron por Allende en 1970 y otra mitad por Rodomiro Tomic, cuya propuesta de reforma agraria era igualmente

8 Esta imagen corresponde a un folleto de la Unidad Popular. Aquí el progreso de la reforma agraria está representado por un hombre entregando una radio a su mujer e hijo. Ella una feliz consumidora, él un buen proveedor. 
profunda. ${ }^{9}$ En las elecciones municipales y parlamentarias de 1971 y 1973, el apoyo de mujeres rurales a la Unidad Popular sube. ${ }^{10}$ De manera que las mujeres campesinas no se oponían a las metas de la reforma agraria, sino que el ideal de familia que ésta promovía, les produjo mayor vulnerabilidad frente de la crisis que la reforma agraria generó.

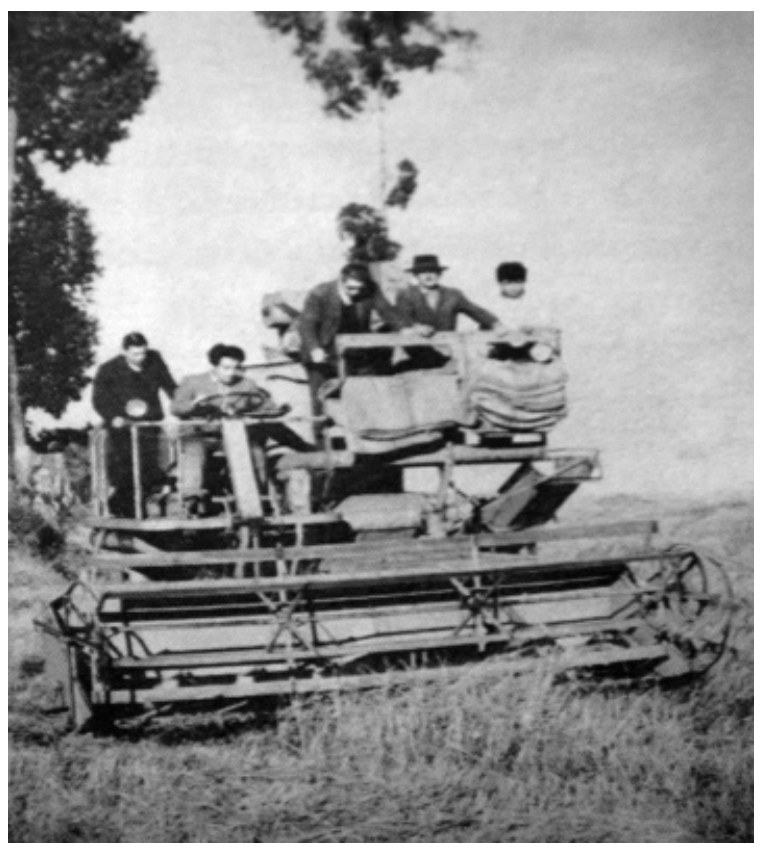

\title{
Referencias Bibliográficas
}

\author{
ALMiNO, A., GÓMEZ, S., KLINE, E. Y RAMÍREZ, P. (1970). \\ Movimiento campesino chileno. (2 vols.). Santiago, \\ Chile: ICIRA \\ ARANDA, X. (1981). Mujer, familia, y sociedad rural: El Valle de Putaendo. \\ Santiago, Chile: Fundación Ford. \\ BENGOA, J. (1990). Haciendas y campesinos: Historia social de la agricultu- \\ ra chilena. Santiago, Chile: SUR.
}

9 En las comunas mayormente rurales del Valle de Aconcagua, 27.5\% de mujeres votaron por Allende y $36.6 \%$ por Tomic. (Dirección de Registro Electoral.)

10 En las elecciones de regidores de abril de 1971, y la elección parlamentaria de marzo de 1973, más de un 36\% de las mujeres en comunas rurales del Valle de Aconcagua, votaron por la Unidad Popular. (Dirección de Registro Electoral.) 
CENTRO DE ESTUDIOS DE LA MUJER (1986).

Hombres y mujeres en Putaendo: Sus Discursos y su visión de la historia. Santiago, Chile: AUTOR.

GÓMEZ, S. Y ECHENIQUE, J. (1988).

La Agricultura chilena: Las dos caras de la Modernización. Santiago, Chile: FLACSO.

GARRETT, P. (1982). La Reforma agraria, organización popular y participación de la mujer en Chile. En León, Magdalena (ed.) Las Trabajadoras del agro. Bogotá: ACEP.

HUERTA, M. (1989). Otro Agro para Chile: La Historia de la reforma agraria en el proceso social y político. Santiago, Chile: CISECCESOC.

JILES, X. (1992). De la miel a los implantes: Historia de las políticas de regulación de la fecundidad en Chile. Santiago, Chile: CORSAPS.

LOVEMAN, B. (1976). Struggle in the Countryside: Politics and Rural Labor in Chile, 1919-1973. Bloomington: University of Indiana Press.

Tinsman, H. (2002). Partners in Conflict: The Politics of Sexuality, Gender, and Labor in the Chilean Agrarian Reform, 19501973. Durham: Duke University Press.

(2001). Good Wives and Unfaithful Men: Sexual Negotiation in the Chilean Agrarian Reform, 19501973. Hispanic American Historical Review. Fall.

(2000). Reviving Feminist Materialism: Gender and Neoliberalism in Pinochet's Chile. SIGNS, 26 (1), pp. 145-188

(1995). Patrones del hogar: Violencia doméstica y control sexual en Chile rural, 1964-1988. En Godoy, L., Hutchison, E., Rosemblatt, K. y Zárate, S. (eds.) Disciplina y desacato: Estudios de genero en la historia de Chile, Siglo XX. Santiago, Chile: SUR/ CEDEM. 
